American Journal of Pharmaceutical Education 2019; 83 (7) Article 7016.

\title{
RESEARCH
}

\section{Inclusion of Socioeconomic Status as an Additional Criterion in Holistic Pharmacy School Admission Processes}

\author{
Rahul Nohria, PharmD, ${ }^{\mathrm{a}}$ Jennifer Adams, PharmD, EdD, ${ }^{\mathrm{b}}$ Gwen E. Garrison, $\mathrm{PhD}^{\mathrm{c}}$ \\ ${ }^{a}$ West Coast University School of Pharmacy, Los Angeles, California \\ ${ }^{\mathrm{b}}$ Idaho State University College of Pharmacy, Pocatello, Idaho \\ ${ }^{\mathrm{c}}$ Claremont Graduate University, Claremont, California \\ Submitted February 12, 2018; accepted July 3, 2018; published September 2019.
}

Objective. To investigate the impact of socioeconomic status as an admissions criterion for pharmacy school admissions.

Methods. Using de-identified data from two PharmCAS application cycles (2012-2013 and 20152016), a new socio-economic status indicator was crafted based on complex parental education and occupation information provided by applicants. The indicator was calibrated on federal standards to ensure uniform composition regardless of the applicant's location. The indicator was then used to describe acceptance patterns within each pharmacy application cycle, explore correlations with other demographic and academic indicators, and develop a regression model to understand the impact of this indicator on applicants' acceptance into pharmacy school.

Results. The new education and occupation (EO) indicator for an applicant's parent(s) provided new insight into complex applicant demographic information. The number of academically qualified applicants that could have received further admission consideration based on identification of a low socioeconomic status for parent one were 2016; $n=435,13 \%, 2103 ; n=767,14 \%$. The EO indicator by itself had limited value for predicting acceptance rates and became less predictive when academic performance variables were incorporated, demonstrating socioeconomic status was not accounted for in admissions.

Conclusion. Based on the Accreditation Council of Pharmacy Education Standards 2016, schools are required to admit a diverse group of students. The addition of the EO indicator will be valuable in identifying diverse and promising future pharmacists during each pharmacy school's holistic review process.

Keywords: socioeconomic status (SES), diversity, admissions, holistic review

\section{INTRODUCTION}

Diversity characteristics of applicants such as race, ethnicity, and socioeconomic status, should be included as part of the definition of what makes a competitive pharmacy school applicant. With a decline in the number of pharmacy school applicants and a rise in both enrollment and the number of pharmacy school graduates nationally since 2003, additional pressures are evident in pharmacy school admissions. As colleges and schools

Corresponding Author: Rahul Nohria, West Coast University School of Pharmacy, 590 N. Vermont Ave., Los Angeles, CA 90004. Tel: 630-346-5274. E-mail: rnohria@westcoastuniversity.edu Note: At the time of study, Drs. Nohria and Adams were affiliated with the American Association of Colleges of Pharmacy, Arlington, VA, and Dr. Garrison was working as a private consultant. of pharmacy consider the make-up of each class, each program must define what makes an attractive Doctor of Pharmacy (PharmD) applicant and which applicant characteristics have potential to help them achieve their educational and broader health care workforce diversity goals. ${ }^{1}$ As pharmacy colleges and schools work to identify the appropriate prospective students for their institutions, there is a need to examine characteristics of the applicant pool to ensure that candidates with the potential to succeed in pharmacy school are not being overlooked during the admissions process. Admissions officers review applications in the admission process to identify characteristics that they believe will help the applicant to be successful in completing a PharmD program. They rely on application information to tell the applicant's "story."

In the 2016 Accreditation Standards and Key Elements for the Professional Program in Pharmacy Leading 


\section{American Journal of Pharmaceutical Education 2019; 83 (7) Article 7016.}

to the Doctor of Pharmacy Degree ("Standards 2016"), the Accreditation Council of Pharmacy Education (ACPE) states, "The college or school develops, implements, and assesses its admission criteria, policies, and procedures to ensure the selection of a qualified and diverse student body into the professional degree program." "2 This accreditation standard guides pharmacy schools in implementing admissions criteria when it comes to considering diversity during holistic applicant review. A holistic admissions process can be defined as a "flexible, highly individualized process by which balanced consideration is given to the multiple ways in which applicants may prepare for and demonstrate suitability" as students and prospective professionals. ${ }^{3}$ Holistic applicant review is crucial to health professions schools because holistic admissions offers the chance for these schools to achieve "core educational goals." "Each school may define diversity differently and have different diversity goals based on applicant characteristics that the institution strives to implement when holistically reviewing each candidate. One aspect of diversity that might be considered by pharmacy schools in order to achieve core educational or diversity goals is socioeconomic status.

Socioeconomic status is a complex term that includes several different components. Socioeconomic status (SES) can be defined as a person(s) position in society determined by social and economic factors. ${ }^{4}$ This can be otherwise defined as a person's "material wealth and noneconomic characteristics such as social prestige and education." However, SES should be focused on social and economic factors and not become a "convenient label to attach to a variety of different combinations of variables. ${ }^{\prime 6}$ Commonly used and accepted measures of SES include parental income, parental education, and parental occupation. ${ }^{4-10}$ Other measures that have been used include free/reduced-cost lunch, co-educational resources, Fee Assistance Program (FAP) eligibility, neighborhood characteristics, and race/ethnicity. ${ }_{4}^{4,10,11}$

Recently, the Association of American Medical Colleges (AAMC) developed an SES Education-Occupation (EO) indicator calibrated to the federal U.S. Department of Labor Standard Occupational Classification (SOC) for use in the American Medical College Application Service (AMCAS). ${ }^{4,9}$ The AMCAS EO indicator uses parental education and occupation to assess a student's SES. Similarly, the American Dental Education Association (ADEA) developed an EO indicator using parental education and occupation and calibrating to the same US Department of Labor Standard Occupational Classification scheme as AAMC, but with specific references to dental applicants' information instead of medical applicants. Per the Associated American Dental Schools
Application Service (AADSAS) application instructions, the EO indicator provides SES information that assists a dental school's review of applicants as part of a holistic review process. ${ }^{12}$ As of now, dental and medical schools are encouraged to use the EO indicator as part of the holistic review process. ${ }^{4,9,12}$

Socioeconomic status has multiple impacts on prospective health care students, and one particularly important impact includes academic achievement. Research has shown that SES correlates to academic achievement, but there is uncertainty on how substantial the impact is. Equality of Educational Opportunity, a report commissioned by the United States Department of Health, Education, and Welfare in 1966, was one of the first publications to shed light on the impact the environment outside of school has on student academic achievement. ${ }^{13}$ Two historical meta-analyses looked at socioeconomic status and the impact it has on student achievement and found there was weak to moderate impact. ${ }^{6,10}$ As noted by White in 1982, there are three possible reasons for a weaker relationship than anticipated, and this includes what is being analyzed, how SES is defined and the markers used to evaluate SES, and finally, how studies are reported. The reporting of studies is especially important as many of the articles White evaluated showed a significant difference between SES and academic achievement, but the authors were not measuring the strength of the relationship but rather if there was an effect. ${ }^{6}$ Sirin also suggests that using a single component or indicator of SES is likely to "overestimate the effect of SES" on student academic achievement. ${ }^{10}$ Articles published since these meta-analyses were published have shown SES can impact academic achievement. 5,8,11,14,15 A 2009 article by Hackman and Farah illustrated the negative impact lower SES has on a child's brain, including on language, executive function, and neurocognitive function. ${ }^{5}$ In addition, students of lower SES with competitive academic achievements exhibit other traits that can help them achieve academic success in health professions schools, such as grit and hardiness which these students developed because of the distance they had to travel to make the same academic achievements as students with higher SES. ${ }^{16}$ Each of these new studies brings a different perspective to the relationship between SES and student academic achievement.

Consideration of diversity characteristics in college admissions has been a complex and at times controversial problem through history beginning with Bakke $v$ Regents of University of California in 1978 to Grutter $v$ Bollinger in 2003 and mostly recently Fisher $v$ University of Texas at Austin in 2013. ${ }^{17-20}$ All three of these cases focused on consideration of race as a diversity characteristic via 


\section{American Journal of Pharmaceutical Education 2019; 83 (7) Article 7016.}

affirmative action and whether it is constitutional to consider race in the admission's process. In the most recent case, Fisher $v$ University of Texas, the Supreme Court ruled in favor of the University of Texas at Austin because the university did have defined and concrete diversity goals and the admissions process at the university did support these diversity goals. Although these cases were focused on consideration of race as a diversity characteristic, they also have relevance when considering other diversity characteristics. During the Fisher case, the American Association of Medical Colleges (AAMC) presented a brief for Amici Curiae, that American Association of Colleges of Pharmacy (AACP) signed, to promote the value of diversity in the classroom. ${ }^{18}$ Within the brief, AAMC states that in order to better serve the prospective diverse patient populations, health care students need to first be engaged with other races and backgrounds within the classroom. In addition, a dissertation by Christina Grabowski supports the idea that holistic admission for medical universities contributes to an increase in academic achievement. ${ }^{21}$ A holistic admissions process must take place in order to bring together an intellectual student population with diverse backgrounds and experiences. Within the holistic review process for medical schools, SES has served as a diversity characteristic, using the EO indicator as one of many components to assess a candidate. ${ }^{7}$

As previously described, SES impacts students' admission into and academic success at dental and medical schools. To date, no previous studies addressing the impact of SES in pharmacy school have been published. To further understand the relationship and impact of SES in pharmacy school, this study was conducted. This study had two aims. The first aim was to evaluate data collected from the pharmacy applicant pool and better understand the prospective student pharmacist population in regards to SES. The second aim was to define an additional diversity characteristic that colleges and schools of pharmacy could use in their application process and to achieve their diversity goals. The intent of the article is not to suggest that SES should supersede any other admission criteria including academic achievements (eg, grade point average (GPA) and pharmacy college admission test (PCAT) scores) or other diversity characteristics, but rather to introduce an additional diversity characteristic to consider. To understand the student pharmacist applicant pool, this study focused on the following questions: can pharmacy schools use an aggregate summary indicator to describe the socioeconomic status of each applicant in the application pool, and how effective are parental education and occupation as predictors of a students' acceptance into pharmacy school? Answering these ques- tions would further enhance the pharmacy school admissions process by collecting additional information in the PharmD application that may help schools holistically review applicants and identify diverse populations.

\section{METHODS}

This study followed specific steps to evaluate the targeted aims. First, existing parental education and occupation data were used to create an SES aggregated indicator, the education-occupation (EO) indicator. A descriptive analysis was conducted to examine the EO indicator and acceptance and non-acceptance patterns. Second, the strength of association was tested using correlation analysis of the EO indicator with other demographic and academic performance indicators. Third, the new indicator was tested along with other demographic and academic performance indicators in a logistical regression to determine the significance $(p<.05)$ of parental education and occupation. The above factors were used to predict the acceptance of a student applicant into pharmacy school. IBM SPSS Statistics Version 25.0 (Armonk, NY) was used to perform the analysis. Chesapeake IRB (Columbia, MD) determined that this project did not constitute human subjects research, and therefore, did not require oversight by an institutional review board.

The study was conducted at AACP and the data for this study was obtained from the Pharmacy College Application Service (PharmCAS), the centralized application service for pharmacy schools. The data used for this study included that from the 2013 (2012-2013) and 2016 (2015-2016) pharmacy school admission cycles. The 2013 admissions cycle was selected because it had the largest applicant pool to date, and the 2016 cycle was selected for comparison against 2013 because it was the most current applicant information available at the time of the study. In accordance with privacy policies, de-identified data were provided to the researchers by the AACP, which owns PharmCAS. Applicants' data were included in the study if the student had applied through PharmCAS in 2013 or 2016 and entered optional information regarding parental education and occupation. Applicants' data were excluded from this research if the student did not fill in parental education and occupation or filled these fields as "unknown." Data of applicants who did not use PharmCAS to apply to pharmacy school or did not complete a PharmCAS form for all their pharmacy school applications were also excluded.

Independent variables in this study were applicants' demographics based on two categories: academic characteristics (undergraduate GPA and Pharmacy College Admission Test [PCAT] scores) and personal characteristics (race/ethnicity, parental education, parental occupation, and 


\section{American Journal of Pharmaceutical Education 2019; 83 (7) Article 7016.}

EO indicator). Undergraduate college GPAs were based on a 4.0 scale. The other academic achievement marker, PCAT scores, was given as a raw score, ranging from 200 to 600 , and as a percentile ranking. These academic achievement markers were used to assess how strongly academic achievements impacted student admission offers.

Applicants had been asked to provide demographic information on the PharmCAS application. First, applicants were asked about their ethnicity (Hispanic or nonHispanic). Then applicants were asked which race they identify with (American Indian or Alaskan Native; Asian; black or African American; Native Hawaiian or other Pacific Islander; or white). Applicants were allowed to indicate more than one race, and many of the race categories allowed the applicant to indicate which race subcategory they identified with. PharmCAS reports all of the data exactly as the applicant indicated to colleges and schools of pharmacy. For the purpose of this study, applicants were grouped into the categories used by the US Census for race/ethnicity: American Indian or Alaskan Native; Asian; black or African American; Hispanic; Native Hawaiian or other Pacific Islander; or white). ${ }^{22}$ As noted above, parental education and occupation were optional questions and self-reported by applicants. Applicants had the opportunity to enter "unknown" for both of these fields in the PharmCAS application. Because educational attainment can be described in progressive, hierarchical terms by degrees, parental education was converted to numerical values: high school or no degree; associate's degree, some college, or certificate of trade or diploma; bachelor's degree; and master's degree, doctorate degree, or professional degree). Parental occupation data were too vast and complicated to group in a simple analysis structure. For calibration, the US Bureau of Labor and Statistics (BLS) Standard Occupational Classification (SOC) system was used. The SOC tracks over 800 occupations and hierarchically groups them into four categories: major, minor, broad, and detailed. The occupation applicant response values were aligned to the SOC major categories and then further aggregated into two categories: clerical, skilled, or service labor worker, or enlisted military; and executive, managerial position, or military officer (Appendix 1). The parental education and occupation data for each parent were given point values and summed to form an EO indicator (Appendix 2).

An EO indicator value of 2 represents the lowest SES class as this would mean a parent achieved the equivalent of a high school education or less and worked as a clerical or skilled worker. An EO indicator value of 6 represented the highest SES class since this would mean a parent achieved an equivalent of at least a master's degree and worked as an administrator or manager. An EO indicator less than 2 indicated missing applicant data and therefore the data were not included in the analysis.

The EO indicator was used to help determine which students should be further reviewed during the admissions process. Applicants were grouped according to academic performance, and based on data of school-reported minimum requirements in PharmCAS for GPA and PCAT composite percentile ranking, an applicant was deemed academically competitive if they achieved $>2.50$ GPA or $>54$ PCAT composite percentile ranking. If an applicant was academically competitive and had at least one parent with an EO indicator of 2, the applicant was noted to be a competitive pharmacy candidate. From there, those applicants noted previously were further inspected to identify those who received an offer and those who did not. Applicants who did not receive an offer were noted as applicants who could be further reviewed during the admission cycle. The outcome (dependent) variable was the number of offers of acceptance into pharmacy school. PharmCAS provided information on how many offers each applicant received. Each applicant was then sorted into one of three categories (applicant received no offers, one offer, or more than one offer).

\section{RESULTS}

During the 2016 admission cycle, 16369 applicants applied through the PharmCAS program and 12744 (78\%) of those applicants provided parental information. During the 2013 admission cycle, 17543 applicants applied through the PharmCAS program, and 13129 (75\%) applicants provided parental information (Table 1). In the 2013 data, $86 \%$ and $78 \%$ of the applicants provided information regarding parent one and parent two education, respectively, and $60 \%$ and $47 \%$ of the applicants provided information regarding parent one and parent two occupation, respectively. In 2016 data, $89 \%$ and $79 \%$ of the applicants provided information regarding parent one and parent two education, and $61 \%$ and $48 \%$ of the applicants provided information regarding parent one and two occupation, respectively. No assumptions were made about the gender or the role of the person the applicant designated as parent one or parent two. It was the applicant's choice who to describe first in the application process.

Table 2 illustrates how many applicants from the 2013 and 2016 cycle were placed in a specific SES category using the EO indicator for parent one and two. Of those applicants from the 2013 applicant cycle, $35 \%$ of the applicants were placed either in the low SES or low to moderate SES category (EO indicator value is between two to three), while $40 \%$ were placed between moderate to very high SES (EO indicator value of four to six) for parent one. In the 2016 data cycle, $36 \%$ of the applicants 


\section{American Journal of Pharmaceutical Education 2019; 83 (7) Article 7016.}

Table 1. PharmCAS Student Demographic (Ethnicity, Parental Education and Occupation), Academic Information (PCAT Composite Percentile Score, GPA), and Acceptance Offer - 2013 and 2016

\begin{tabular}{lrr}
\hline Variable & $\begin{array}{c}\mathbf{2 0 1 2 - 2 0 1 3} \\
\text { No. (\%) }\end{array}$ & $\begin{array}{r}\mathbf{2 0 1 5 - 2 0 1 6} \\
\text { No. (\%) }\end{array}$ \\
\hline Total students who applied & 17543 & 16369 \\
Major race-ethnicity & $12540(72)$ & $11736(72)$ \\
Minority race-ethnicity & $3201(18)$ & $3744(23)$ \\
Applicants with no or incomplete parent one data & $4414(25)$ & $3625(22)$ \\
Applicants with no or incomplete parent two data & $6462(37)$ & $5734(35)$ \\
Applicants with parental one education information & $15101(86)$ & $14635(89)$ \\
Applicants with parental two education information & $13603(78)$ & $12976(79)$ \\
Applicants with parental one occupation information & $10455(60)$ & $9941(61)$ \\
Applicants with parental two occupation information & $8149(47)$ & $7873(48)$ \\
Applicants who provided PCAT Score & $14060(80)$ & $12719(78)$ \\
Applicants who provided GPA & $17343(99)$ & $16089(98)$ \\
Applicants who received at least one acceptance offer & $12236(70)$ & $13039(80)$ \\
\hline
\end{tabular}

Abbreviations: PharmCAS = Pharmacy College Application Service; PCAT = Pharmacy College Admission Test; GPA=grade point average

were placed between low SES and moderate SES, while $42 \%$ of the applicants were placed between moderate to very high SES for parent one. Of those applicants from the 2013 applicant pool, 34\% of the applicants were placed either low SES or low to moderate SES, while $29 \%$ of the applicants were placed between moderate to very high SES for parent two. In the 2016 data cycle, $35 \%$ of the applicants were placed either in low SES or low to moderate SES, while $30 \%$ were placed between moderate to very high SES for parent two.

To further identify potential competitive applicants who are placed as low SES based on the EO indicator for parent one or parent two. Tables 3 and 4 illustrate the relationship between applicants' SES (who could be further reviewed while not receiving an offer) and GPA. The results suggest that 767 and 723 applicants who were identified as low SES using the parent one and parent two EO indicator, respectively, did not receive an offer but had a GPA greater than 2.50 during the 2013 admission cycle. During the 2016 admission cycle, 435 and 408 applicants who were identified as low SES using the parent one and parent two EO indicator did not receive an offer but had a GPA greater than 2.50.

Tables 5 and 6 illustrate the relationship between applicants who did not receive an offer while achieving a competitive PCAT composite percentile ranking. The results suggest that 190 and 189 applicants who were identified as low SES using the parent one and parent two EO indicator respectively did not receive an offer despite having placed in the $55^{\text {th }}$ PCAT composite percentile ranking during the 2013 admission cycle. During the 2016 admission cycle, 79 applicants and 85 applicants who were identified as low SES using the parent one and parent two EO indicator respectively did not receive an offer despite that they placed in at least the $55^{\text {th }}$ PCAT composite percentile ranking.

Table 2. Distribution of Applicant Data Regarding Parent 1 and 2 EO Indicator ${ }^{\mathrm{a}}$ for 2013 and 2016 Application Cycles

\begin{tabular}{lccccc}
\hline & \multicolumn{2}{c}{ 2013 Application Cycle } & & \multicolumn{2}{c}{ 2016 Application Cycle } \\
\cline { 2 - 3 } & $\begin{array}{c}\text { Parent One } \\
\text { Frequency } \\
\text { N (\%) }\end{array}$ & $\begin{array}{c}\text { Parent Two } \\
\text { Frequency } \\
\text { N (\%) }\end{array}$ & & $\begin{array}{c}\text { Parent One } \\
\text { Frequency } \\
\text { N (\%) }\end{array}$ & $\begin{array}{c}\text { Parent Two } \\
\text { Frequency } \\
\text { N (\%) }\end{array}$ \\
\hline EO Indicator & $1915(11)$ & $3725(21)$ & $1551(10)$ & $3225(20)$ \\
Missing Both Ed and Occupation Data & $2499(14)$ & $2737(16)$ & $2074(13)$ & $2509(15)$ \\
Not Enough Ed or Occupation Data & $2811(16)$ & $2857(16)$ & $2764(17)$ & $2782(17)$ \\
Low SES (EO=2) & $3280(19)$ & $3126(18)$ & $3172(19)$ & $2934(18)$ \\
Low to Moderate SES (EO=3) & $2335(13)$ & $1948(11)$ & $2244(14)$ & $1889(12)$ \\
Moderate to High SES (EO=4) & $2409(14)$ & $1833(10)$ & $2321(14)$ & $1738(11)$ \\
High SES (EO=5) & $2294(13)$ & $1317(8)$ & $2243(14)$ & $1292(8)$ \\
Very High SES (EO=6) & $17543(100)$ & $17543(100)$ & $16369(100)$ & $16369(100)$ \\
\hline Total & & &
\end{tabular}

${ }^{a}$ EO Indicator is defined as Education-Occupation Indicator 
American Journal of Pharmaceutical Education 2019; 83 (7) Article 7016.

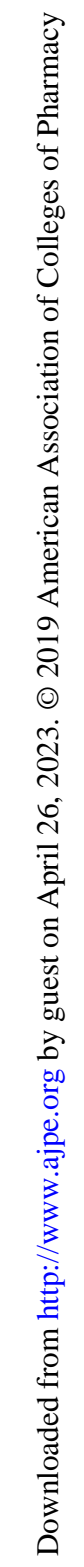
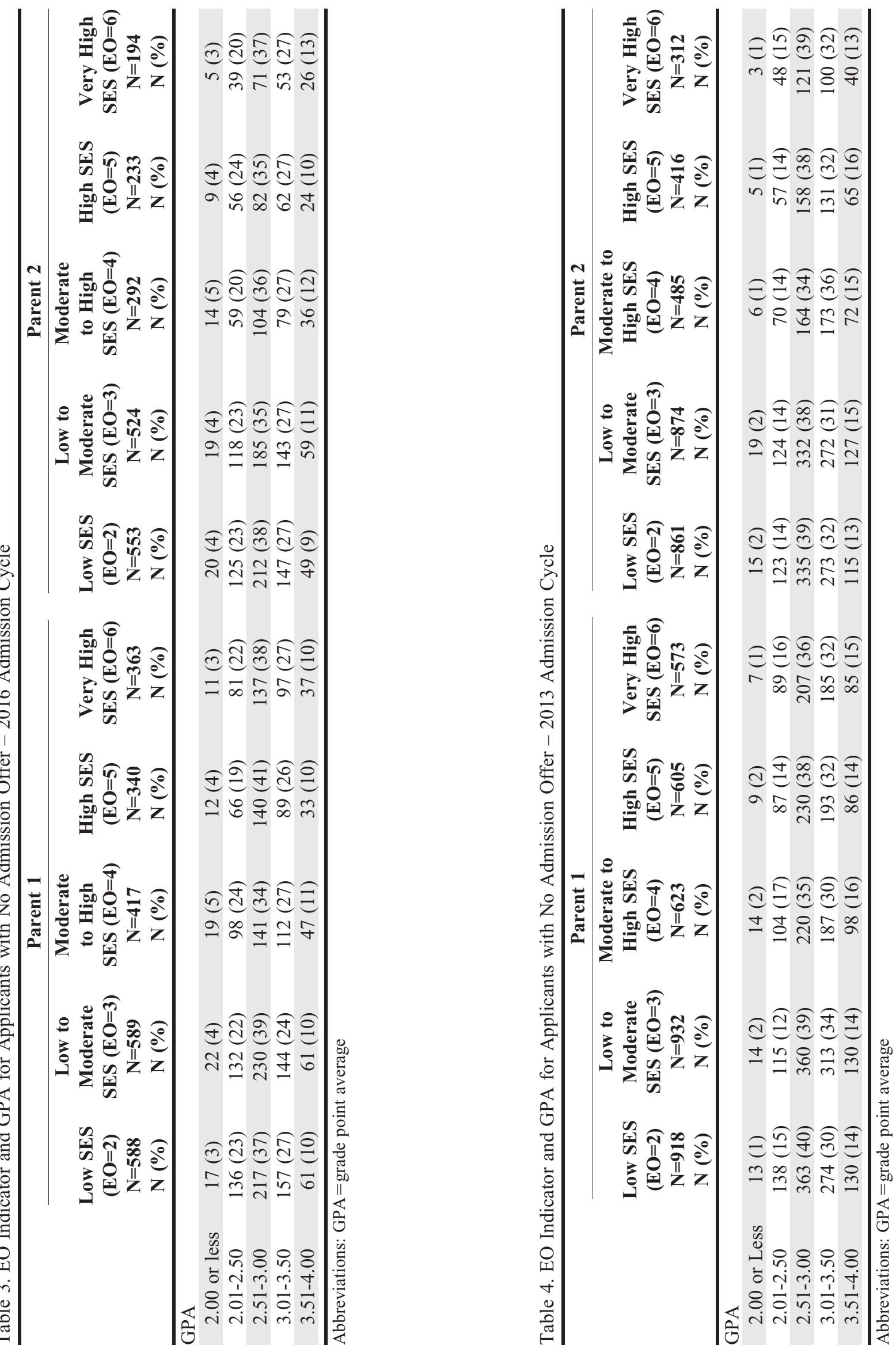
American Journal of Pharmaceutical Education 2019; 83 (7) Article 7016.

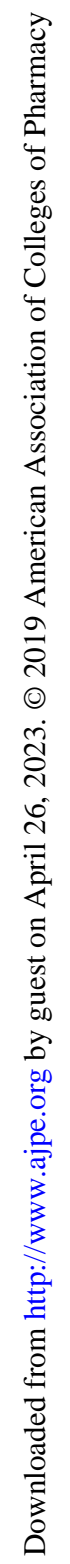
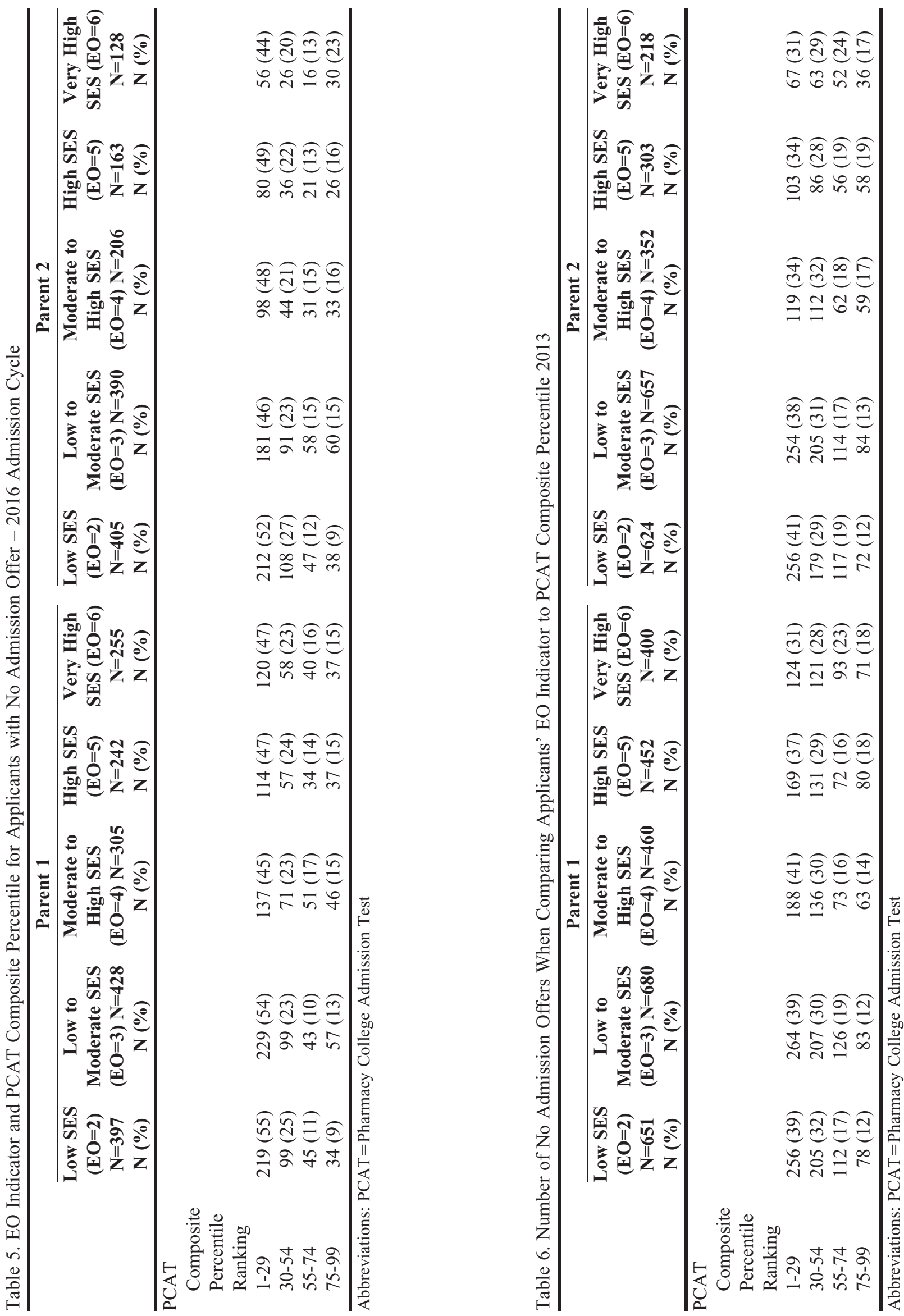
American Journal of Pharmaceutical Education 2019; 83 (7) Article 7016.

Two analyses were conducted to test the EO indicator with acceptance into pharmacy school. The analysis tested the strength of the relationship of the EO indicator among other demographic and academic characteristics. Table 7 demonstrates that the EO indicator is significant but weakly correlated $(\mathrm{r}=.09$ with .10 for parent one and two, respectively) while academic performance was significant and moderately correlated $(\mathrm{r}=.38$ with .35 for Grouped GPA and PCAT in four groups, respectively).

Next, a logistic regression analysis was conducted that included parent one and two EO indicators, as well as race and academic performance markers. Table 8 illustrates the logistic regression model with acceptance offer as the dependent variable, and EO indicators, other demographic factors, and finally academic performance markers as independent variables. The results show that academic performance measures were the strongest predictors for a student receiving an admission offer (standardized beta $=$ 6.32 for GPA), while the parental EO indicators and PCAT markers were predictors (standardized beta $=1.03$ and 1.04 for parent one and two EO indicator) for receiving acceptance offers. In addition, the model was able to correctly classify the acceptance offer $83 \%$ of the time.

\section{DISCUSSION}

Pharmacy school admission processes are increasingly complex. It is becoming more imperative for pharmacy schools and colleges to identify candidates who will help them achieve their educational and health care workforce diversity goals. ${ }^{1-3}$ Adding socioeconomic status as another criterion during the admissions process will help pharmacy education identify prospective applicants who will help them achieve these goals.

Both the American Association of Medical Colleges (AAMC) and American Dental Education Association (ADEA) have created an EO indicator to help identify the socioeconomic status of applicants. ${ }^{7,9,12}$ The EO indicator constructed in this research incorporates information similar to that collected by AAMC and ADEA: parental occupation and parental education. The AAMC has validated the EO indicator as an instrument to measure SES. ${ }^{9}$ The results from this study indicated that 435 and 79 applicants from the 2016 pharmacy admission cycle who had low SES based on the EO indicator for parent one, had a competitive GPA (GPA > 2.5) and a competitive PCAT percentile ranking $(>54 \%)$, respectively. Clearly, schools are not assessing socioeconomic status as the odds ratio is 1.03 and 1.04, which is close to representing no relationship exists between acceptance offer and EO indicator for both parent one and two. By using the EO indicator, pharmacy schools during the 2016 cycle could have targeted competitive, low SES applicants to help achieve core university goals. ${ }^{3}$

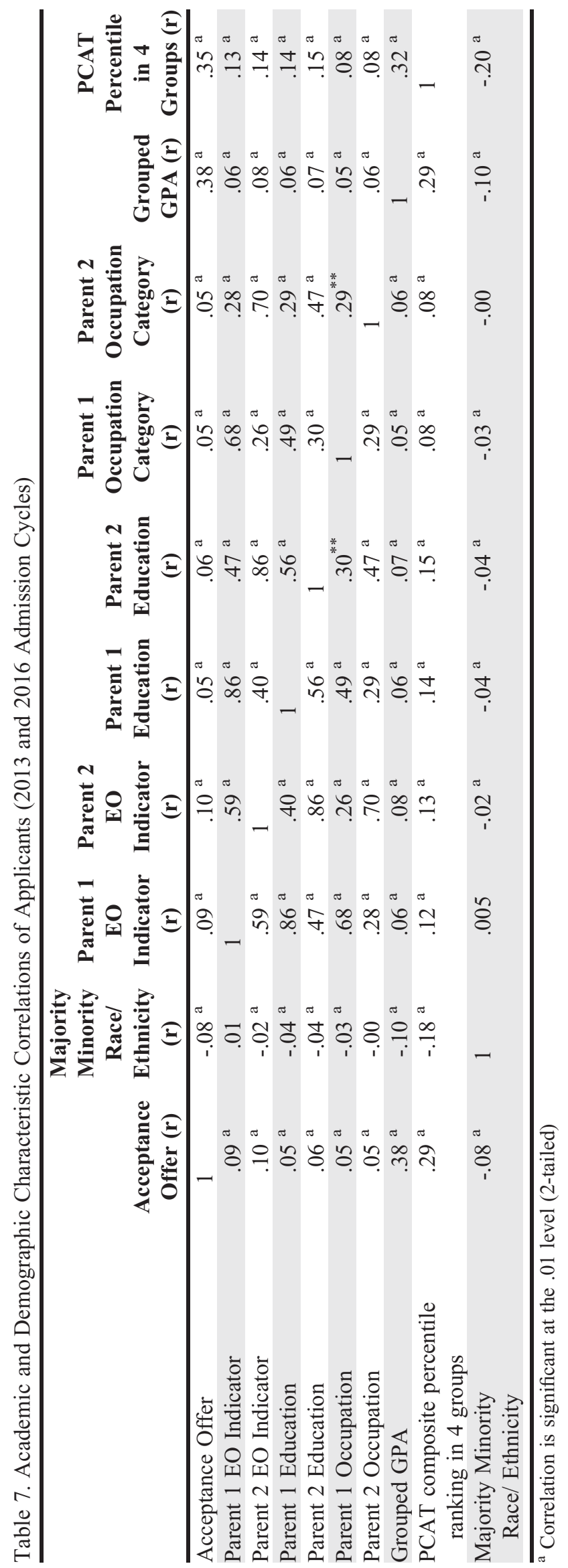




\section{American Journal of Pharmaceutical Education 2019; 83 (7) Article 7016.}

Table 8. Regression Model for EO Indicator, Race, PCAT, and GPA (2013 and 2016 Admission Cycles)

\begin{tabular}{lccccc}
\hline & & & & \multicolumn{2}{c}{$\mathbf{9 5 \%}$ CI } \\
\cline { 4 - 6 } & $\mathbf{B}$ & SE & Exp(B) & Lower & Upper \\
\hline Parent 1 EO Indicator & .03 & .01 & 1.03 & 1.01 & 1.06 \\
Parent 2 EO Indicator & .04 & .01 & 1.04 & 1.02 & 1.06 \\
Majority Minority RE & -.03 & .03 & .97 & .91 & 1.03 \\
PCAT Composite Percentile Ranking & .03 & .001 & 1.03 & 1.03 & 1.03 \\
GPA & 1.84 & .04 & 6.32 & 5.83 & 6.86 \\
Constant & -6.06 & .14 & .00 & & \\
\hline
\end{tabular}

$\mathrm{X}^{2}=6019.328, p<.001$ with $82.8 \%$ of the applicant correctly classified

A decline is seen between the number of low SES students who were competitive academically and did not receive an admission offer between the 2013 and 2016 admission cycles. This decline could be directly related to the number of seats in pharmacy schools increasing while the applicant pool decreased. The number of candidates included in the study in 2013 but not given an admission offer was 5306, while the number of candidates in 2016 who did not receive an admission offer was 3330 . However, this decline can be explained by the similar percentage of academically competitive low SES candidates who did not receive an offer letter in both admission cycles. In 2013, 14\% of the 5306 applicants had low SES while in 2016, 13\% of 3330 applicants had low SES while maintaining a competitive GPA. When looking at PCAT percentile ranking, in 2013, $4 \%$ of the 5306 applicants had low SES while in 2016, $2 \%$ of the 3330 applicants had low SES.

Aside from schools achieving core diversity goals, applicants who come from a background of having a lower SES can help classmates develop empathy for and understanding of patients who come from similar backgrounds. ${ }^{18,21}$ Furthermore, lower SES applicants often possess qualities such as grit and hardiness, which has helped them be as academically competitive as peers who come from higher SES backgrounds. ${ }^{16}$ Pharmacy schools are required by the Accreditation Council of Pharmacy Education (ACPE) to admit a diverse student body, and in order to achieve that, a holistic review process is necessary. ${ }^{2}$ By using the EO indicator during the admission process, universities further enhance the holistic admission process any may identify candidates that will allow them to not only achieve core diversity and educational goals, but also enrich the classroom with their unique perspectives on health care.

This study made the assumption that the interview process was equal between all qualified applicants. However, the interview process could be one reason why low SES students are not given admission offers. In addition, the information provided by PharmCAS did not include which applicants were re-applicants. Applicants who were reapplying could have been at a disadvantage or an advantage. Because the information students provided regarding parental occupation and education was voluntary, there was a potential for bias and inability to evaluate the SES of all applicants. Some possible considerations for future PharmCAS applications would be to include predetermined options for parental education and occupation and to make the EO information a required section of the application so that a majority of applicants could be evaluated using the EO indicator.

\section{CONCLUSION}

Because of the Accreditation Council of Pharmacy Education's stance on pharmacy institutions admitting diverse applicants, adding markers to identify an applicant's socioeconomic status can help schools achieve their diversity goals. This study shows there are prospective applicants with low SES backgrounds who could succeed in a PharmD program if they were easier to identify in the admissions process. The EO indicator is another tool that can help the pharmacy admissions community continue their move toward a more holistic approach to all admissions decisions.

\section{ACKNOWLEDGMENTS}

The authors are grateful to American Association of Colleges of Pharmacy and the Pharmacy College Application Service for providing the 2012-2013 and 20152016 applicant data.

\section{REFERENCES}

1. Student Applications, Enrollments and Degrees Conferred. American Association of Colleges of Pharmacy Website. https:// www.aacp.org/research/institutional-research/student-applicationsenrollments-and-degrees-conferred. Published 2018. Accessed January 8, 2018.

2. American Council Pharmaceutical Education. Accreditation standards and key elements for the professional program in pharmacy leading to the Doctor of Pharmacy degree (Standards 2016). https:// www.acpe-accredit.org/pdf/Standards2016FINAL.pdf. Published February 2015. Accessed January 8, 2018. 


\section{American Journal of Pharmaceutical Education 2019; 83 (7) Article 7016.}

3. Addams AN, Bletzinger RB, Sondheimer HM, White SE, Johnson LM. Roadmap to diversity: integrating holistic review practices into medical school admission processes. Washington DC: Association of American Medical Colleges; 2010. https://members.aamc.org/eweb/ upload/Roadmap $\% 20$ to\%20Diversity\%20Integrating $\% 20$ Holistic $\%$ 20Review.pdf. Accessed January 8, 2018.

4. Galobardes B, Shaw M, Lawlor DA, Lynch JW, Smith GD. Indicators of socioeconomic position (part 1). J Epid Comm Health. 2006;60(1):7-12.

5. Hackman DA, Farah MJ. Socioeconomic status and the developing brain. Trends in Cognitive Sciences. 2009;13(2):65-73.

6. White KR. The relation between socioeconomic status and academic achievement. Psych Bulletin. 1982;91(3):461.

7. Grbic D, Jones DJ, Case ST. Effective practices for using the AAMC socioeconomic status indicators in medical school admissions. Assoc of Am Med Coll. 2013;1-7.

8. Ardila A, Rosselli M, Matute E, Guajardo S. The influence of the parents' educational level on the development of executive functions. Dev Neuropsych. 2005;28(1):539-560.

9. Grbic D, Jones DJ, Case ST. The role of socioeconomic status in medical school admissions: validation of a socioeconomic indicator for use in medical school admissions. Acad Med. 2015;90(7):953-960. 10. Sirin SR. Socioeconomic status and academic achievement: a meta-analytic review of research. $R$ Educ Res. 2005;75(3):417-453. 11. Malecki CK, Demaray MK. Social support as a buffer in the relationship between socioeconomic status and academic performance. School Psych Q. 2006;21(4):375.

12. Socioeconomic status and EO indicator. http://www.adea.org/ GoDental/ADEA_AADSAS_Application/Personal_information. aspx\#sthash.NyleIgGS.dpbs. Updated 2018. Accessed January 8, 2018.
13. Coleman JS, Campbell EQ, Hobson CJ, et al. Equality of educational opportunity. Washington, DC: US Dept of Health, Education, and Welfare; 1966.

14. Davis-Kean PE. The influence of parent education and family income on child achievement: the indirect role of parental expectations and the home environment. J Family Psych. 2005;19(2):294.

15. Battle J, Lewis M. The increasing significance of class: the relative effects of race and socioeconomic status on academic achievement. J Poverty. 2002;6(2):21-35.

16. Ray R. Reassessing student potential for medical school success: distance travelled, grit, and hardiness. Military Med. 180(4S). 17. Rosenbaum S, Teitelbaum J, Scott J. Raising the bar on achieving racial diversity in higher education: the United States Supreme Court's decision in Fisher v University of Texas. Acad Med. 2013;88(12):1792-1794.

18. Abigail Noel Fisher v. University of Texas at Austin Brief for Amici Curiae Association of American Medical Colleges et al in support of respondents.Washington DC: Association of American Medical Colleges; 2013.

19. Epstein L, Knight J. Peircing the veil: William J. Brennan's account of regents of the University of California v Bakke. Yale Law \& Policy Review. 2001;19:341-379.

20. Grutter v. Bollinger Certiorari United States Court Appeals Fifth Circuit. Washington, DC: Supreme Court; 2003.

21. Grabowski, C. The impact of a holistic review process on a new medical school [dissertation]. Rochester, Michigan: Oakland University. 2016.

22. Race \& Ethnicity. Washington, DC: US Department of Commerce; 2017. 


\section{American Journal of Pharmaceutical Education 2019; 83 (7) Article 7016.}

Appendix 1. Summary of Coding for Parent Education and Parent Occupation

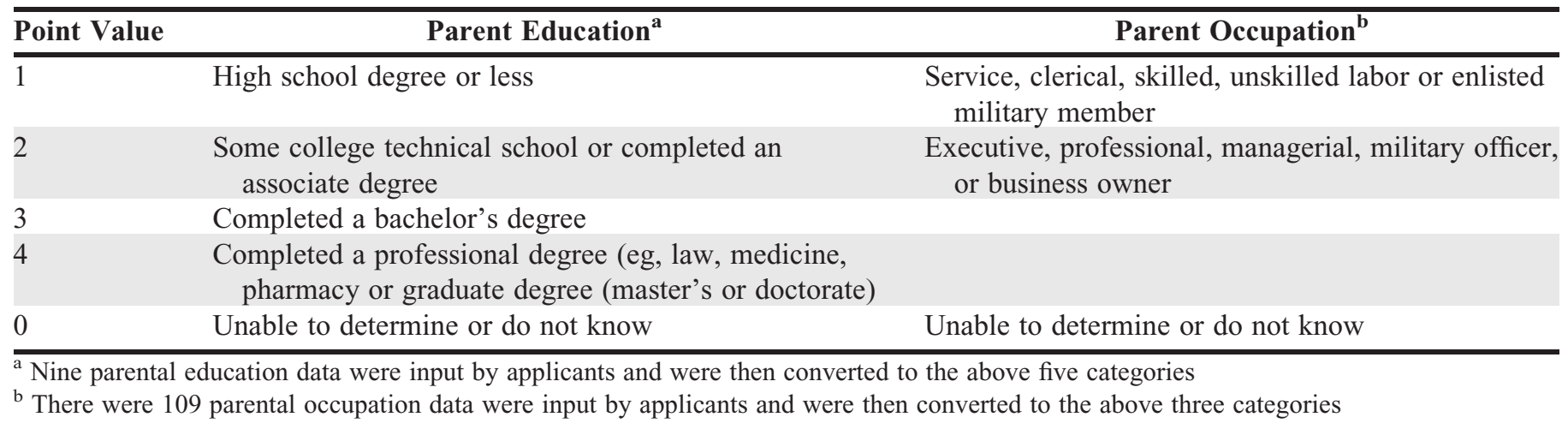

Appendix 2. Education-Occupation Indicator for a Student Applicant

\begin{tabular}{llcc}
\hline & & \multicolumn{2}{c}{ OCCUPATION } \\
\cline { 2 - 3 } & & $\begin{array}{c}\text { Executive, Managerial } \\
\text { (2 Points) }\end{array}$ & $\begin{array}{c}\text { Service, Clerical, Skilled and } \\
\text { Unskilled Labor (1 point) }\end{array}$ \\
\hline EDUCATION & Professional or Graduate Degree (4 points) & EO-6 & EO-5 \\
& Bachelor's Degree (3 Points) & EO-5 & EO-4 \\
& Some College, Tech or Associate's Degree (2 Points) & EO-4 & EO-3 \\
& High School Degree or Less (1 Point) & EO-3 & EO-2 \\
\hline
\end{tabular}

